\title{
Lifestyle journalism
}

\section{Blurring boundaries}

Kristensen, Nete Nørgaard; From, Unni

Published in:

Journalism Practice

DOI:

$10.1080 / 17512786.2011 .622898$

Publication date:

2012

Document version

Peer reviewed version

Citation for published version (APA):

Kristensen, N. N., \& From, U. (2012). Lifestyle journalism: Blurring boundaries. Journalism Practice, 6(1), $26-41$. https://doi.org/10.1080/17512786.2011.622898 


\title{
LIFESTYLE JOURNALISM \\ Blurring boundaries
}

\section{Nete Nørgaard Kristensen and Unni From}

University of Copenhagen and University of Aarhus, Denmark

netenk@hum.ku.dk and imvuf@dac.au.dk

Published in Journalism Practice, 2012, vol. 6(1) 26-41, (C) The Author(s) 2012, Available at: http://www.tandfonline.com/doi/abs/10.1080/17512786.2011.622898

\begin{abstract}
The article argues that, in contemporary journalism, the boundaries between lifestyle journalism and cultural journalism are blurring. The discussions of the article are based in comprehensive empirical studies, more specifically a content analysis of the coverage of lifestyle, culture and consumption in the Danish printed press during the twentieth century and the first decade of the twenty-first; and secondly, interviews with Danish cultural journalists and editors. The studies reveal that the coverage of lifestyle is expanding and that culture, lifestyle and consumption are today contiguous - sometimes even inseparable - subject matters, which even for journalists are difficult to separate. The findings are interpreted in the light of especially Jansson's approach to mediatization of consumption as an expression of more general socio- and media cultural transformations of society.
\end{abstract}

KEYWORDS consumer journalism; content analysis; cultural journalism; lifestyle journalism; mediatization; printed press

\section{Introduction}

In this article we argue that, in contemporary journalism, the boundaries between lifestyle journalism (such as journalism on fashion, food and psychology), cultural journalism (such as journalism on movies, music and theatre) and consumer journalism (such as journalism on cars, technology and travels) are blurring. These blurring boundaries make it difficult to categorize at least some subjects or stories as belonging to either one or the other journalistic category: news desks cover music and food, for example, as equivalent matters by articulating them as expressions both of culture, lifestyle and/or consumption. Furthermore, journalistic genres are blending, since product presentations, pre-announcements, reviews, reports and interviews not only include information on cultural expressions and product characteristics but also provide discussions of taste and aesthetics and thus, at different levels, guide the citizen and/or consumer in his or her way of life. Even though all of these subjects and generic approaches are usually categorized as "soft news" in opposition to "hard news", their mutually blurring boundaries indicate that soft news not only challenges existing definitions of journalism, it also challenges existing definitions of cultural journalism in particular as a distinct journalistic subject. Therefore, we analyse lifestyle journalism in comparison with cultural journalism and consumer journalism.

As a point of departure, the article discusses this classical hard news/soft news distinction in journalism, including how cultural journalism, lifestyle journalism and consumer journalism differentiate themselves from the traditional definition of journalism as hard news, as well as how these subjects are both distinct from and similar to one another. These theoretical 
discussions form the foundation of a discussion of selected findings from both a quantitative and qualitative content analysis of the coverage of lifestyle, culture and consumption in the Danish printed press during the twentieth century and the first decade of the twenty-first century. Since empirical research on lifestyle journalism is very limited, we discuss how the coverage of lifestyle has been expanding in the printed press in some detail, and how it increasingly borrows from and influences coverage of culture and other topics. Secondly, we analyse interviews with journalists and editors which both challenge and confirm the content analysis and the argument about blurring boundaries: culture, lifestyle and consumption are today contiguous - sometimes even inseparable - subject matters, which are difficult to define or demarcate distinctively even for journalists. The specific approaches to these topics adopted by specific newspapers are, however, important trademarks of the news desks and point to lifestyle journalism as important in an increasingly competitive media landscape.

Our empirical findings are discussed in the light of media institutional changes within the Danish media system; e.g. we address how the blurring boundaries of form, content and mode of address reflect structural transformations in the Danish media system. Furthermore, the empirical findings are discussed in the light of Jansson's (2002) discussions of the mediatization of consumption, since he argues that in contemporary society traditional cultural products are launched, communicated and discussed as consumer goods, while functional consumer products are presented as cultural artefacts with priority given to their symbolic value over their mere functional usefulness. This precisely indicates*and accounts for the fact*that lifestyle journalism as topic or journalistic field can function to distinguish and profile the individual newspapers. Specific soft news priorities - literature, food, living, travelling, and so on - serve to brand the individual newspaper in an increasingly competitive news media landscape. This also points at mediatization as a process of "accommodation" (Schulz, 2004) that is characterized by media industries and actors (for example, political actors, actors of sport and entertainment) adapting - or more specifically, how actors "adapt to the rules of the media system trying to increase their publicity and at the same time accepting a loss of autonomy in a close interrelation. On the other hand, the media also benefit from such transactions since they make politics more newsworthy and conveniently formatted" (Schulz, 2004, pp. 89-90). This simultaneous focus on both media systemic transforma- tions and processes of mediatization is a productive approach to explaining the blurring of boundaries of, changing modes of address of and increasing complexity in defining topics such as lifestyle, culture and consumption.

\section{Hard News, Cultural Journalism and Lifestyle Journalism}

Defining what constitutes lifestyle journalism is complicated, not least because journalism research within the field is limited and scattered. One way of identifying what constitutes lifestyle journalism is to define what it is not, or, how it differs from journalism as such. Journalism researchers generally distinguish between "hard news" and "soft news" by discussing their differences, similarities and blurring boundaries. Several criticize soft news for increasingly invading hard news - and interpret this invasion as an expression of the tabloidization, commercialization - even corruption - of journalism and the news media as such hereby point to the subject of the story as important - that is, whether the content concerns matters of public relevance or lighter matters relating to the private sphere.

Other researchers emphasize the differing production processes which characterize hard news and soft news, respectively (see Boczkowski, 2009 for an overview), pointing to time as an important aspect, including such factors as whether or not a story is breaking news, whether it calls for immediate publication or can be published independently of a spe- 
cific timeframe. From this perspective the question of time is of greater importance than the question of content or substance.

No matter whether or not one interprets genre, angle and/or temporality as more significant than topic, one might argue that both lifestyle journalism and cultural journalism fall within the "soft news" category, since both usually concern matters relating to the private sphere and do not represent breaking news. In the following discussion, we shortly introduce essential characteristics of cultural journalism, lifestyle journalism and at least parts of consumer journalism in order to accentuate the relations between these journalistic fields.

As Hovden and Knapskog (2008), Janssen et al. (2008) and Golin and Cardoso (2008) accentuate in different ways, cultural and industrial transformations have expanded the boundaries of, for example, cultural journalism, which is, consequently, a heterogeneous concept in contemporary journalism, crossing the boundaries of such domains as politics, celebrity culture, lifestyle and consumption. This blurring of boundaries between subjects as well as hard news and soft news can be related to the introduction of service journalism in the second part of the twentieth century - in Scandinavia in the 1980s (Eide, 1992; Hjarvard, 1995). Service journalism provides the reader with guidance on matters of consumption and choices of softer aspects of life in an increasingly complex society and everyday life, and thus addresses the reader as an individual rather than a member of the public - as a consumer rather than as a citizen. Both Eide (1992) and Hjarvard (1995) point to the increasing element of guidance in cultural journalism (both pre-announcements and reviews of cultural products and experiences) as evidence of this tendency. In doing so, they implicitly point to a blurring of the boundaries between cultural journalism and service journalism - or service journalism as a characteristic aspect of cultural journalism. Accordingly, we might understand service journalism as an adaptation or reinterpretation of the classical genre of cultural journalism, the review, as practised in product announcements and tests of a variety of lifestyle products and consumer goods such as children's clothing, wine, and cookbooks. Furthermore, Hjarvard (1995) argues that lifestyle journalism coincides with consumer journalism, since, in terms of content, lifestyle journalism covers a range of consumer-related subjects and objects - living/the home, cars, fashion, food - but also more abstract cultural phenomena such as wellness, subcultures, psychology, human relations, and everyday life. Even within consumer journalism, Sundvor (2008, p. 64) emphasizes the compound nature of this journalistic topic in terms of both content and form: it traverses different topics - politics, economy, business, culture and lifestyle*and genres, from the uncritical product presentation to the critical, investigative story.

This introductory discussion indicates that not least lifestyle journalism is as much a matter of discursive elements and ways of addressing its readers and users, as it is a question of content or time of publication/deadline. It raises at least two central research questions:

RQ1: Since when and how are lifestyle subjects covered by newspapers - and has this coverage changed?

RQ2: How are lifestyle subjects negotiated by journalists and news desks within their daily routines?

\section{Methodology}

This article is based on comprehensive empirical studies of lifestyle journalism and cultural journalism in a Danish context (see also From, 2010; Kristensen, 2010; Kristensen and From, 2011). The analysis was conducted using two empirical approaches: a content analysis and a smaller production study. Both studies adopt a broad approach to the same research subject, lifestyle and cultural journalism, and are based on the assumption (introduced theoretically 
above, and to be explained and developed empirically in the following discussion) that lifestyle journalism and cultural journalism today exist in a continuum between art, popular culture, lifestyle and consumption.

In our analysis, we will draw primarily on selected findings from the content analysis of the coverage of lifestyle, culture and consumption during the twentieth century and the first decade of the twenty-first in four Danish newspapers with different editorial profiles (centreleft broadsheet, Politiken; liberal/conservative broadsheet, Jyllands-Posten; tabloid newspaper, Ekstra Bladet; and in 2008, free newspaper, metroXpress). Even though the current media landscape is characterized by a number of media platforms, the content analysis is not cross-medial, but rather focuses on the transformation of the printed press in an increasingly cross-mediated and converging media culture. Given that the study covers a long period of time during which everyday life, cultural expressions and media culture have undergone great changes, we have chosen years of analysis, designated as key years relating to different media-institutional and technological changes in the Danish media system, with potential influence on the coverage of lifestyle, consumption and culture in the press. More specifically, we designed a constructed one-week sample from each newspaper for each of the following years: 1890, 1920, 1935, 1960, 1970, 1995, and 2008. Subjects included as lifestyle are: fashion (including beauty, health, shopping); cars (including motorcycles, boats); travels (including tourism); design/living (including garden- ing and interior decoration), food (including beverages, restaurants) and everyday life (including children, relationships). ${ }^{1}$ The findings of this study answer questions of what and how much has been covered when, while qualitative examples from the sample, which consists of 2813 articles in total, will be included to allow us to elaborate on how these subjects are covered. This question of "how" is further elucidated and contextualized by findings from the production interviews with journalists and editors (seven respondents who work for the different newspapers included in the content analysis).

More specifically, the empirically-based discussions in the remainder of the article explore whether the assumption that coverage of "soft news" has been increasing, in this case by Danish newspapers, is valid, and moreover which specific subjects are covered within the overall framework of lifestyle journalism. Furthermore, the empirical discussions address the question of lifestyle as converging/overlapping with other subjects and as discursive mode of address.

\section{More Extensive, but Changing Coverage of Lifestyle and Consumption}

Based on the content analysis and exemplified by qualitative examples, this first part of the empirical discussion explores what lifestyle subjects are covered by the Danish press, and how these subjects are covered. On the one hand, the content analysis documents an increasing coverage of topics relating to lifestyle and consumption in Danish newspapers during the twentieth century. On the other hand, the press coverage of lifestyle is not a new phenomenon. However, the mode of address or approach has changed.

One sign of the increasing editorial priority given to lifestyle journalism in the printed newspapers relates to Barnhurst and Nerone's (2001) concept of the social mapping of content. Whereas Barnhurst and Nerone (2001, p. 245) identify an increasing segregation between topics relating to the public sphere and civil society (or what could be interpreted as an increasing segregation of hard news and soft news, if one chooses to perceive content or subject as a constitutive aspect of this distinction), this study points to an increasing organization into topics relating to either culture or lifestyle, and thus a segregation of topics within the "soft news" category. In the second half of the twentieth century, newspapers, through bars on the top of the pages, such as "House and Garden" or "Family and Consumer" (JyllandsPosten, 1970), divided their stories into increasingly narrow categories, indicating that prec- 
edence is given to everyday life and consumption. In 2008 these strategies for mapping content resulted in magazine-like sections such as "Living" (Jyllands-Posten, 2008), "Saturday Life" (Politiken, 2008) or "Coup" (Ekstra Bladet, 2008). These sections present editorially marked and segregated content relating to lifestyle and consumption. This development reflects tendencies within the magazine press, and more recently, in primetime television (Brundson, 2003; Christensen, 2010; Mckay, 2000; Povlsen, 2007), where we have also witnessed an increasing priority given to very specific subjects such as living, garden, food and wellness, targeted at very specific audiences. As in the magazine press, the continual changing and renewal of the special sections of newspapers can be interpreted as a permanent accommodation to changing reader interests and, thus, as part of the branding of the newspapers by means of special sections reflecting the cultural profile of the newspaper (Kristensen, 2010).

On the one hand, this increasing segregation of topics contradicts this article's argument about the blurring of boundaries. On the other hand, it indicates the historical development of lifestyle journalism into a distinct journalistic subject - or a subject of journalistic priority which can be seen in light of a developing consumer society, an increasing interplay (and interdependence) between the press and advertisers, and changing relations between the public and the private sphere as reflected in the press. Accordingly, not only an increasing number of sections, but also an increasing number of stories concern these subjects (Table 1), even though stories on different aspects of lifestyle and consumption have been covered during most of the twentieth century.

TABLE 1

The coverage of overall subjects by year $(N=2813)$

\begin{tabular}{|c|c|c|c|c|c|c|c|}
\hline & 1890 & 1920 & 1935 & 1960 & 1970 & 1995 & 2008 \\
\hline \multicolumn{8}{|l|}{ Politiken $(N=1100)$} \\
\hline Culture & $98(52)$ & $93(104)$ & $88(91)$ & 79 (135) & $63(116)$ & 77 (178) & $65(160)$ \\
\hline Lifestyle & & $2(2)$ & $8(8)$ & $15(25)$ & $19(35)$ & $12(28)$ & $17(41)$ \\
\hline Culture and lifestyle & $2(1)$ & $5(6)$ & $4(4)$ & $6(10)$ & $18(34)$ & $11(25)$ & $18(45)$ \\
\hline \multicolumn{8}{|l|}{ Jyllands-Posten $(N=907)$} \\
\hline Culture & $92(24)$ & $97(33)$ & $80(31)$ & $70(88)$ & $74(162)$ & $80(192)$ & $65(145)$ \\
\hline Lifestyle & & $3(1)$ & $21(8)$ & $21(26)$ & $17(38)$ & $16(39)$ & $28(63)$ \\
\hline Culture and lifestyle & $8(2)$ & & & $9(11)$ & $9(19)$ & $4(9)$ & $7(15)$ \\
\hline \multicolumn{8}{|l|}{ Ekstra Bladet $(N=673)$} \\
\hline Culture & & $80(37)$ & $89(88)$ & $66(76)$ & $77(65)$ & $92(109)$ & $68(141)$ \\
\hline Lifestyle & & $4(2)$ & $10(10)$ & $33(38)$ & $20(17)$ & $5(6)$ & $21(43)$ \\
\hline Culture and lifestyle & & $15(7)$ & $1(1)$ & $2(2)$ & $2(2)$ & $3(4)$ & $12(25)$ \\
\hline \multicolumn{8}{|l|}{ metroXpress $(N=133)$} \\
\hline Culture & & & & & & & $64(85)$ \\
\hline Lifestyle & & & & & & & $27(36)$ \\
\hline Culture and lifestyle & & & & & & & $9(12)$ \\
\hline
\end{tabular}

Values are percentages with numbers in parentheses.

The blurring boundaries are, however, also documented more explicitly by the content analysis, since it shows an increasing hybridization of culture and lifestyle-related matters within the same article in the 2008 sample: whereas the distinction between culture and lifestyle/consumption was preserved in the printed press throughout most of the twentieth century, in 2008, more than one in 10 articles touched upon topics relating to both culture and lifestyle/consumption. This mixing of topics seems to have been intensifying, with some fluctuations, especially starting in the second part of the twentieth century (Table 1). This hybrid 
tendency is most noticeable in the broadsheet Politiken and least so in the broadsheet Jyllands-Posten.

In broader terms, the historical changes in the coverage of lifestyle in Danish newspapers can be summarized in three categories: "stability", "the periodical Golden Age" and "new subjects" (Table 2).

Table 2 confirms an increasing coverage - and increasing variety - of lifestyle-related topics, especially in the second half of the twentieth century. The year 1995, however, stands out, since some topics almost disappear from the agenda (e.g. fashion - a subject that had experienced the periodical Golden Age in the previous decades); the coverage of other topics drops somewhat, even though these topics do not disappear entirely from the agenda (e.g. everyday life), while the coverage of a range of yet other topics increases in 2008 (e.g. food or living). This might explain the fact that 1995 seems to represent a year of transition. In the following discussion, these historical changes will be presented in more detail, with an emphasis on the analysis of qualitative examples of changes in the mode of addressing the topics.

\section{TABLE 2}

Changes in the coverage of living, fashion, everyday life, food, travelling, and cars

\begin{tabular}{lccccccc}
\hline & $\begin{array}{c}\mathbf{1 8 9 0} \\
(\mathbf{N}=\mathbf{7 9})\end{array}$ & $\begin{array}{c}\mathbf{1 9 2 0} \\
\mathbf{N = 1 9 2})\end{array}$ & $\begin{array}{c}\mathbf{1 9 3 5} \\
(\mathbf{N}=\mathbf{2 4 1})\end{array}$ & $\begin{array}{c}\mathbf{1 9 6 0} \\
\mathbf{N}=\mathbf{4 1 1})\end{array}$ & $\begin{array}{c}\mathbf{1 9 7 0} \\
(\mathbf{N}=\mathbf{4 8 7})\end{array}$ & $\begin{array}{c}\mathbf{1 9 9 5} \\
(\mathbf{N}=\mathbf{5 9 0})\end{array}$ & $\begin{array}{c}\mathbf{2 0 0 8} \\
(\mathbf{N}=\mathbf{8 1 1})\end{array}$ \\
$\begin{array}{l}\text { Living/interior } \\
\quad 3(2)\end{array}$ & $2(3)$ & $1(3)$ & $3(13)$ & $3(16)$ & $1(8)$ & $5(42)$ \\
$\begin{array}{l}\text { fecoration } \\
\text { Everion }\end{array}$ & & $1(2)$ & $7(16)$ & $9(37)$ & $7(33)$ & $1(5)$ & $4(31)$ \\
$\begin{array}{l}\text { Food } \\
\text { Travelling }\end{array}$ & $1(1)$ & & $2(5)$ & $12(51)$ & $15(73)$ & $5(28)$ & $8(62)$ \\
Cars & & $1(1)$ & $2(5)$ & $2(7)$ & $2(9)$ & $3(15)$ & $4(34)$ \\
Total & $1(1)$ & & $2(10)$ & $3(16)$ & $4(25)$ & $5(40)$ \\
& $4(3)$ & $5(5)$ & $12(29)$ & $31(129)$ & $33(163)$ & $15(87)$ & $27(219)$ \\
\hline
\end{tabular}

Values are the percentages of the analysed articles each year (numbers in parentheses), which were coded for the given subject $(N=2813)$. In 2008 metroXpress was included in the sample.

\section{Living - Stable Coverage}

One of the topics which has experienced steady coverage during the entire twentieth century quantitatively speaking is "living" (including garden/design/interior decoration), as it is a topic in 1-5 per cent of the sampled stories in each year of analysis. From a more qualitative point of view, the coverage of the subject, and consequently the way in which readers are addressed, has changed considerably. Two articles relating to gardening will serve to exemplify this changing mode of address.

The report "A Thousand and One Varieties of Fruit" (Politiken, 3 September 1960, under the page heading "The House in the Garden") reports on the many different and exotic fruit bushes and trees which can be observed in the garden of The Royal Veterinary and Agricultural University (today the Faculty of Life Sciences at the University of Copenhagen). The article emphasizes the mere existence of this impressive collection and its methods of cultivation, addressing the enthusiastic garden-owner who could visit the garden. That is, the article rather narrowly focuses on the garden as aesthetic expression and public good. Decades later the article "Spring in the Windowsill" (metroXpress, 4 March 2008, under the page heading "House and Garden") exemplifies how the home and the garden are articulated as lifestyle projects rather than factual information or everyday routine in contemporary journalism (Christensen, 2010). The article presents the very ordinary presence of house plants on the windowsill and the specific choice of their colours as an expression of a strategic action and 
part of a larger staging of a tasteful and orderly home in a busy daily life: in other words, it points to culture and lifestyle as processes and phenomena rather than products or objects. More generally, the cases exemplify that even though living is a topic which has experienced rather stable coverage and thus attention from the press in quantitative terms throughout the twentieth century, the journalistic approach to*that is the presentation and communication of*the subject has changed considerably, from addressing, informing and educating the readers as (part of a) public to addressing the readers as individuals. It thus exemplifies the theoretical argument of Eide (1992) and Hjarvard (1995) regarding service journalism introduced above, as well as blurring boundaries of living, interior decoration and design in contemporary journalism. We will return to and elaborate on this argument later in the article, since similar transformations can be observed within the coverage of other lifestyle topics.

\section{Fashion - "The Golden Age"}

Fashion (including beauty, health and shopping) represents an example of a lifestyle subject which experienced a "periodical Golden Age" measured in terms of the extent of its coverage during the twentieth century. In the analysis, coverage of fashion was most extensive in 1935, 1960 and 1970, whereas it is less important in contemporary journalism (Table 2), just as it has a rather ambiguous status from an editorial perspective, an issue we will return to below. The periodical Golden Age might be explained by the fact that the Danish magazine market was in the early stages of its development in the 1960s and 1970s (Povlsen, 1995). Thus, contrary to the contemporary fashion magazine market, the number of specialized magazines on fashion and beauty in the 1960s and 1970s, which would have been able to compete with newspaper coverage of the subject, was limited. As we will discuss below, newspapers today cannot and will not compete with the many specialized fashion magazines available when it comes to setting the agenda and/or reporting the latest news from the catwalks, new fashion trends, fabrics, or accessories. However, fashion is not absent from the printed press. Instead, coverage is closely linked to the reader profile of the newspaper. The business-oriented newspaper Jyllands-Posten, for example, approaches fashion from a commercial angle. This is exemplified by a story in the business section about the movie Sex and the City (5 October 2008) on the opening day of the movie. The article gives priority not to the movie as an aesthetic expression but as a vehicle for co-branding commodities such as fashion trends and products (shoes, clothing, etc.) and more importantly, ways of life. The article thus exemplifies the blurring boundaries between lifestyle journalism and cultural journalism, since fashion is approached as a representation of ways of life and a symbolic marker of taste and lifestyle (Jansson, 2002; Kristensen, 2010). Unlike Jyllands-Posten, the free daily metroXpress covers fashion in a more traditional way by reporting from fashion weeks and presenting fashion and beauty commodities which can be purchased on the way home from school or work. It thus offers coverage similar to that characteristic of the 1960s and 1970s, only supplemented by consumer information such as price and purchase location. Therefore, while fashion is today not a lifestyle topic of top priority in the printed press, it is a topic which journalists feel obligated to cover, even though they also find it very difficult to do so, not least due to competition from the specialized national and international magazine press.

\section{Everyday Life}

Like the coverage of fashion, the coverage of everyday life - such as children, family and relationships - was most extensive in the printed press in the 1960s and 1970s, which means it had its "Golden Age" decades ago (Table 2). This is emphasized by page headings such as "The Family" (Ekstra Bladet, 1960), "Ekstra Break Recess" (Ekstra Bladet, 1970), "For the Entire Family" (Jyllands-Posten, 1970), which exemplifies the emerging social mapping of content by the newspapers of that time. Again, specific articles demonstrate how the coverage of the subject has changed qualitatively during the last 40 or 50 years. 
The article "Supporting the Child Rather Than Making Demands" (Politiken, 1 April, 1970), for example, concerns a new association aimed at helping children with reading difficulties. Accordingly, the article "The School Where Boys Can Be Boys" (Politiken, 4 October 1970) tells the story of Bernadotteskolen, a school which seeks to help children, especially boys, through difficult stages of their lives; while the article "Well-being for the Whole Family" (Politiken, 4 October 1970) reports on an association that strives to improve the wellbeing of a residential neighbourhood by introducing common areas and shared activities. Even though these stories concern human interest, the angle is on neither the individual nor matters of consumption. Rather, the articles adopt a more general public perspective by informing the readers on social responsibility and community initiatives* or public interests. In other words, they address the question of children and everyday life as a matter of public interest and hereby address their readers as citizens rather than individuals and/or consumers. In 2008, a more consumer-oriented approach could be seen to supplement this public perspective, which is exemplified by an article in the free daily metroXpress ( 2 April 2008, p. 21) that reviews computer games for children with a focus on "a nice weekend". The short article, "Fun for Kids", is written from the child's perspective, inviting four children to describe their experiences with five computer games. It gives priority to the consumer perspective, and thus exemplifies the research discussed above which highlights how a service element and individualization have increasingly come to characterize lifestyle and consumer journalism since the last decades of the twentieth century (e.g. Eide and Knight, 1999).

Whereas fashion and everyday life seem to have experienced declining coverage in the past few decades, the quantitative analysis also discloses that a range of new topics emerged in the newspapers, especially in the second part of the twentieth century. In other words, it reveals an altered focus within lifestyle journalism.

\section{Food - Travelling - Cars}

As a new subject, food (including beverages and restaurants) entered the newspapers in the second part of the twentieth century (Table 2), and is covered more extensively in contemporary newspapers. ${ }^{2}$ Furthermore, we can observe a changed mode of address and thus discourse in the coverage of food which is similar to the transformations in the coverage of home and garden stories discussed previously. In the 1960s and 1970s, articles focused on everyday life and everyday meals and instructed the housewife in how to create inexpensive, nice food. Today the coverage of food includes good advice, recipes, reviews and expressions of taste and lifestyle, and the subject is therefore approached not only as guidance to cultural and/or gastronomic products or experiences (e.g. restaurant reviews) but also, like fashion, as a representation of ways of life and a symbolic marker of taste and lifestyle. Moreover, these articles are often accompanied by large and diverse illustrations, which indicate that reading them is intended to be a pleasurable activity. From a broader perspective, one characteristic of lifestyle journalism and cultural journalism is precisely the visual dimension, which provides not only documentation (if at all), but also (or rather) visual and cultural experiences (Kristensen and From, 2011). For example, on Wednesday 2 April 2008, the broadsheet Jyllands-Posten published a two-page spread collage of articles on confirmation party menus and catering, including both price comparisons of catering menus and homemade menus, a handwritten shopping list and budget, illustrated recipes for a three- course party menu and an article on an appropriate wine menu. It thus illustrates a very mixed generic and visual approach to food. Correspondingly, food has been given high priority on television and in the magazine press for the past decade (Brunsdon, 2003; Christensen, 2010) with emphasis on the social, personal, aesthetic and symbolic aspects of food (Povlsen, 2007).

Likewise, printed newspapers began covering consumer goods such as travel/ tourism and cars (along with motorcycles and boats) more extensively in the second half of the twentieth century concurrently with the development of consumer society. From a more qualita- 
tive perspective, we can, for example in relation to the coverage of cars, observe a consistent interest in technical consumer details, but in contemporary coverage we also observe a considerable interest in the symbolic and social value of these consumer goods as markers of taste and lifestyle, as was the case with the changing approach to the coverage of home and garden, fashion and food. For example, the one-and-a-half page article "We Test: Borgward Isabella" (Politiken, 6 April 1960) described and tested the driving capacities and technicalities of a new car in great detail, under subheadings such as "Motor and Gearbox", "Good Roadhandling", "The Rear-end Skids", "The View" and "Equipment". Fifty years later, the interview-based article "Cars and Brotherhood" (Jyllands-Posten, 6 June 2008) tells the personal story of a motor journalist and Land Rover enthusiast who is quoted as saying: "A Land Rover has charisma, a curious origin, a fascinating history and suits the ballroom just as well as the stable. It is the key to a national and international spiritual community. And it reflects how simply it can be done, how little it takes to meet the need to get from point A to point B." Even though the article includes traditional technical details on the functionality of the Land Rover as means of transportation or consumer good, the primary approach, as emphasized by the headline of the article and the choice of genre, is the symbolic and social value of the car as symbol of lifestyle and means to social networking and community.

To sum up, the content analysis documents structural changes in the press coverage of subjects such as living, fashion, everyday life, food and cars during the twentieth century (the "what"), while the qualitative examples point to discursive changes in this coverage (the "how"), indicating blurring and closely connected boundaries between lifestyle journalism, consumer journalism and cultural journalism. The blurring boundaries can, on the one hand, be interpreted as a result and reflection of hybridizations of phenomena and subjects in society as such. On the other hand, the journalistic approach to and coverage of these socio-cultural subjects itself potentially influences the cultural circuit, and thus lifestyle journalism itself can also be seen to contribute to the very blurring of the boundaries. This points towards the relevance of analysing journalists' interpretation and approach to different topics in the production phase.

\section{Lifestyle Journalism from a Production Perspective}

In the following discussion, we will elaborate on how lifestyle is negotiated as a subject by the seven journalists and editors whom we interviewed about their work. On the one hand, the analysis displays how editorial priority and importance are attributed to lifestyle journalism by contemporary newspapers as part of their branding strategy or specific editorial profile. On the other hand, the analysis confirms the (blurring) boundaries between lifestyle, consumer and cultural journalism from an editorial perspective.

\section{Editorial Importance in a Changing Society and Competitive Media Landscape}

Both journalists and editors argue that lifestyle issues are relevant topics which (their) newspapers, at least to some extent, should cover, in a manner that is tailored to the specific target group of the newspaper. They reflect upon how modern (everyday) life has changed and that newspapers nowadays need to show interest in and cover how people live their lives, reflect contemporary existence or living, and provide guidance and information on daily life.

One of the journalists, Poul Tvilum (from the broadsheet Jyllands-Posten), articulates the shift in the coverage of lifestyle and consumption from a focus on consumer-related issues as a political topic to a focus on lifestyle-related issues as reflections of everyday life in this way:

In the old days, consumer journalism was about spoiled meat and consumer complaints about the quality of clothing and so on. We realized very early on that what we needed 
to gain popular appeal was a focus on lifestyle and weight loss and healthy diets, etc.... We find that modern people's consumer behaviour has changed ... It's no longer just about consuming stuff here and now. There's also a focus on how we live together, how people interact with each other.

This statement confirms that lifestyle journalism is not only a matter of consumer advice, but also - and increasingly so - a matter of guiding the reader on immaterial topics and "the good life" in an increasingly complex society (Hjarvard, 1995).

During our interviews, journalists and editors rarely mentioned specific lifestyle topics as more important than others for their newspapers, but they explained how techniques such as reader surveys are used to pinpoint specific lifestyle issues as important at particular times. In other words, they argue that the coverage of specific lifestyle issues by the newspapers is closely related to trends within society and in the media as such. For example, food is, as mentioned, a topic that has occupied magazines, television programmes - and newspapers. In the words of Ditte Giese (from the broadsheet Politiken):

They do reader surveys all the time, and the second section, Culture, is always rated very highly. This is also how they discovered that their readers are really interested in food, which is why they introduced a food supplement. You can measure it quite clearly.

At the same time, journalists and editors implicitly indicate that lifestyle topics can serve to brand their newspapers. Poul Tvilum (from the broadsheet Jyllands-Posten) argues that the establishment of a specific issue as important by the newspaper is closely connected to the interplay between the image/brand of the newspaper, the readers' interest in the subject and the potential to attract advertisers:

We focus a lot on health in general. We focus a lot on consumer electronics, and motors and diet, for example...because we think it's important for our brand and because people are interested and because there's money in it. That's the trinity we focus on, you might say.

Thus, editors and journalists argue that lifestyle, as journalistic topic, is a relevant and conventional part of modern newspapers. Accordingly, they contend that the priority given to specific issues by the newspapers reflect trends within society and the media as such. They furthermore indicate, as we have already touched upon above, that lifestyle journalism appears to symbolize and mirror a more general trend within journalism: specific issues, such as food, can be covered as consumer journalism (a political debate on quality), as culture (Asian food culture) and/or as lifestyle (how to choose a wedding menu that reflects your identity or "way of life"). In the following analysis, we will elaborate on these processes of negotiation in the journalistic field, which precisely point to blurring boundaries within journalism.

\section{Blurring Boundaries from a Production Perspective}

Both editors and journalists find that most cultural and lifestyle topics are quite distinctive and thus clearly distinguishable. Consequently, they have a clear conception of what, from their point of view, characterizes culture, lifestyle and consumption, respectively, as journalistic topics. They share a common understanding and interpretation of subjects such as theatre, movies and literature as "culture" - or as issues belonging to the cultural section. At the same time, they agree that lifestyle journalism is a more ambiguous topic than cultural journalism. That is, they agree that the boundaries of subjects are, in fact, indefinite, and can thus be interpreted very differently by various journalists and newspapers. And these differing in- 
terpretations, as it turns out, are closely linked to the editorial organization of the news desks and, as already indicated, to the editorial profile of the newspaper.

As discussed above, fashion is a recurring example which, according to journalists, can be addressed as an issue relating either to lifestyle, culture and/or consumption, depending on the chosen angle for the specific article, just like food. Fashion is thus an issue under continuous negotiation at news desks, and journalists, even from the same newspaper, disagree on how to approach it and, consequently, where to place it in the newspaper. Nina Ettrup (from the free daily metroXpress) describes it as follows:

In fact, I consider fashion a classic lifestyle topic ... Of course, it overlaps with consumer journalism. We had this discussion during Copenhagen Fashion Week. Can you put it in the culture section? And I really don't think you can ... you might as well put it in the money/business section, because it's also about money. Or domestic news. Or foreign news. It's not culture in my view. Unless you turn it into something about what DJs are playing at Fashion Week, or something. But with pure fashion, models, and should it be blue or green, I think that's lifestyle.

The statement demonstrates how the particular focus or approach to the topic in a specific article determines who or which desk writes the story, and where the story is placed in the newspaper. That is, the angle of the story is more important than the subject. It also points to the business section as very important in the discussion of subjects related to lifestyle and culture, because articles on topics such as fashion are often related to economics and marketoriented perspectives, and are accordingly covered in this section and not only in sections on culture, lifestyle and/or consumption. This was precisely exemplified by the alreadymentioned article in the broadsheet Jylland-Posten on the movie Sex and the City - which was published in the business section and covered the opening of the new movie not as a cultural event but as a vehicle for co-branding fashion commodities and, consequently, lifestyles. This confirms one of the opening arguments of this article: that different topics can be addressed differently, as either hard news or soft news. It furthermore points to the theoretical argument indicated above: that the question of blurring boundaries not only relates to culture, lifestyle and consumption, but also to subjects traditionally interpreted as hard news (such as economics and politics).

According to Ditte Giese (from Politiken), fashion is an issue for the culture section, even though she simultaneously points to the ambiguity of the subject and its position on a continuum between lifestyle and cultural journalism. More specifically, she explains how her newspaper approaches fashion differently from the weekly and monthly fashion magazines, which, according to her, have a consumer-oriented approach to the topic with priority given to guidance and consumer information.

Fashion goes in the culture section in Politiken, but our angle is not to show "three things in purple" from a consumer angle, but to analyse and contextualize fashion, for example with a long, in-depth article on Fred Perry on the occasion of his 100th birthday ... We want to have it, but at the same time, we know that people who are interested in fashion buy the magazines, read fashion blogs and go to fashion weeks ... And it [fashion] has to be there, because it would seem strange for us as a newspaper not to include it.

These statements thus confirm the ambiguity of fashion as a journalistic topic in newspapers, which was also indicated by the content analysis: fashion is something newspapers cannot ignore, but which they, at the same time, find difficult to cover in a manner that is distinctively different from the competing magazine press. 
Jakob Levinsen (from Jyllands-Posten) also confirms the empirical conclusion of the content analysis that the categorization of fashion as either lifestyle journalism or consumption depends on the local organization of the newspaper, and that the priority of a specific topic must be seen in the light of the overall brand of the newspaper:

It's more a question of how the newspaper is organized, where it [fashion] arbitrarily ends up. At our place some fashion is lifestyle material with the big fashion shows, and some of it is down at H\&M [low-end high street chain] level.

Levinsen's statement points to the influence of subject-external factors (the organizational setting and brand of the newspaper) on the interpretation of, approach to and priority given to a specific issue, in this case fashion. Different newspapers, sections and journalists have their specific fields of interest and specific trademarks. From this perspective the editorial organization and the journalist as agent/subject determine whether a story is characterized as consumer, lifestyle or cultural journalism, not the story as object.

To summarize, from a production perspective, journalists negotiate the definition and placement of lifestyle issues such as food and fashion, and they confirm that some subjects can be defined or interpreted as belonging to the culture, lifestyle and/or consumer desk, depending on the mode of address and the angle of the individual article. These negotiations of boundaries, placement and mode of address are facilitated by the editorial organization of newspapers, which assign priority/importance (or the opposite) to specific issues such as their trademarks, brands or profiles.

\section{Blurring Boundaries and Strategic Trademarks from a Theoretical Perspective}

In this article we have approached the issue of blurring boundaries in lifestyle journalism in different ways: through the quantitative analysis and the qualitative examples, we have documented that it is difficult to demarcate lifestyle as a journalistic topic in contemporary journalism: our analysis reveals that boundaries between subjects such as lifestyle, consumption and culture are blurring at the textual level, and consequently so are different modes of address. From the perspective of the producers*journalists*the question of boundaries is constantly being negotiated. These negotiations are themselves manifest in the blurring boundaries between subjects and modes of address.

One framework for interpreting these changes is the development of the Danish media system, including transformations in the relationship between the public and the private, between hard news and soft news. The Danish media system has, in line with global media developments, changed from a party press at the turn of the twentieth century, where Danish newspapers were mouthpieces for political parties and viewpoints, to an omnibus press targeted at a broad audience (that is, a cultural institution providing public service for private money) and most recently to commercial media institutions in a competitive media market, where political and cultural profiles are necessary market strategies. For example, Hjarvard (2010) documents a political parallelism (see Hallin and Mancini, 2004) between Danish broadsheets and niche newspapers and their readers that is particularly evident in the editorial opinions and occasionally apparent in the journalistic content of these newspapers as well. Similarly, Kristensen (2010) and Kristensen and From (2011) document a cultural parallelism between different newspapers and their readers, since readers read the newspapers with which they identify culturally*or the newspapers which confirm their cultural orientation. Accordingly, in relation to lifestyle journalism, this article has documented increasingly demarcated sections within individual newspapers and a changed mode of addressing readers in relation to a range of topics related to lifestyle - from public service to private service, 
from society to the individual - and that the editorial organisation and the brand of the newspaper/media institution today influence the specific priority given to and negotiation of specific topics, including how specific lifestyle topics are covered and approached. It is thus possible to speak of simultaneous processes or strategies of inclusion and exclusion by newspapers: the many stories and issues which might potentially be interpreted as and subjects for lifestyle journalism force the newspapers to select and prioritize specific topics, combinations of stories and generic approaches, which in the end serve to differentiate, characterize or brand the individual newspaper. The argument of inclusion of topics thus relates to the fact that everything is potentially open to interpretation and representation as lifestyle, while the argument on exclusion relates to the fact that the newspapers brand themselves through very specific topics and journalistic approaches.

Even though our empirical data regarding texts and content is limited to the printed press, the more extensive blurring of boundaries beyond the typical soft news areas might thus be explained in light of the increasingly competitive media landscape of the past decades, which has forced newspapers to develop new or different approaches to a range of topics, since the printed press cannot compete with other media platforms such as television and the Internet when it comes to "breaking" stories. In other words, newspapers cannot compete on timeliness and deadlines. Consequently, other news values have become important.

These media institutional changes reflect the more general socio-cultural transformations which are incorporated in the concept of mediatization of culture and society (Hjarvard, 2008; Jansson, 2002; Schulz, 2004). Jansson (2002) elucidates the close connections between media, economics and cultural and social processes in Western societies and cultures through a discussion of how media products, cultural objects and phenomena, mediatized culture and consumption - including lifestyle - are today linked to an economic, industrial logic which circulates symbolic and semiotic signs rather than fulfilling basic physiological needs. From a theoretical perspective, and departing from the concept of "culturalization", Jansson argues that traditional cultural products are launched and articulated as consumer goods while consumer goods are presented as cultural products. Accordingly, we argue that media, actors and cultural industries in a broad sense "accommodate" (Schulz, 2004) to each other and that the blurring of boundaries between topics in contemporary lifestyle and cultural journalism can be explained as a result of but also as contributing to precisely these processes. We do not argue that cultural journalism or consumer journalism are being replaced by lifestyle journalism, but rather that these journalistic topics are often issues of negotiation, just as they are placed in sections and on news desks where they are (constantly) processed by journalists in ways which construct specific (soft) topics as lifestyle journalism, cultural journalism and/or consumer journalism. Accordingly, one might argue that precisely these journalistic negotiations and construc- tions influence the more general articulation of lifestyle as cultural phenomenon in society.

Even though the empirical perspective of the discussions and arguments presented in this article is Danish, the discussions and results are of broader, international relevance, since they identify more general characteristics of and changes within lifestyle journalism, its production and mode of address. Furthermore, the changing, expanding and blurring boundaries of the form, content and address of lifestyle journalism can be interpreted as a reflection of changes within and blurring of boundaries of journalistic topics and genres as such, documented by and discussed in relation to not least political journalism. This indicates that journalism constantly challenges, reformulates and expands different topics and agendas such as lifestyle, culture or politics.

\section{NOTES}


1. Each article could, if relevant, be coded for up to three different subjects - in order to grasp the presumed increasing blurring of boundaries between lifestyle, consumption and culture. Due to a very limited number of articles within some subject categories, e.g. health, these were included in the "other" category in the analysis.

2. One of the newspapers included in the study, Politiken, even introduced the Sunday section FOOD in March 2009 (http://www.politikenannoncer.dk/9913/09/04\%20MAD:\% 20Danmarks\%20eneste\%20dagbl\%20, accessed 19 July 2011).

\section{REFERENCES}

BARNHURST, KEVIN G. and NERONE, JOHN (2001) The Form of News, New York: Guilford. BOCZKOWSKI, PABLO (2009) "Rethinking Hard and Soft News Production", Journal of Communication 59(1), pp. 98-116.

BRUNDSDON, CHARLOTTE (2003) "Lifestyling Britain: the 8-9 slot on British television", International Journal of Cultural Studies 6(1), pp. 5-23.

CHRISTENSEN, CHRISTA LYKKE (2010) “Livsstilsprogrammer. Hverdag og underholdning ["Lifestyle Television Programmes. Everyday life and entertainment"]", in: Hanne Bruun and Kirsten Frandsen (Eds), Underholdende tv [Entertaining Television], Aarhus: Aarhus University Press, pp. 212-45.

EIDE, MARTIN (1992) Den Fjerde Servicemakt - noter til forståelse av norsk veilednings- og kampanjejournalistikk [The Fourth Service Estate], Bergen: Institut for Massekommunikasjon.

EIDE, MARTIN and KNIGHT, GRAHAM (1999) "Public/Private: service journalism and the problems of everyday life", European Journal of Communication 14(4), pp. 525-47.

FRANKLIN, BOB (1997) Newszak and News Media, Oxford: Oxford University Press.

FROM, UNNI (2010) "The Reading of Cultural and Lifestyle Journalism", Northern Lights 8, pp.157-75.

GOLIN, CIDA and CARDOSO, EVERTON (2009) "Cultural Journalism in Brazil: academic research, visibility, mediation and news values", Journalism 10(1), pp. 69-89.

HALLIN, DANIEL C. and MANCINI, PAOLO (2004) Comparing Media Systems, Cambridge: Cambridge University Press.

HJARVARD, STIG (1995) Nyhedsmediernes rolle i det politiske demokrati [The Role of the News Media in Political Democracy], København: Statsministeriets Medieudvalg.

HJARVARD, STIG (2008) "The Mediatization of Society. A theory of the media as agents of social and cultural change", Nordicom Review 29(2), pp. 105-34.

HJARVARD, STIG (2010) "The Views of the News: the role of political newspapers in a changing media landscape", Northern Lights 8, pp. 25-48.

HOVDEN, JAN FREDRIK and KNAPSKOG, KARL A. (2008) "Kulturjournalistikken i det norske journalistiske feltet" ["Cultural Journalism in the Norwegian Journalistic Field"]", in: Karl A. Knapskog and Leif O. Larsen (Eds), Kulturjournalistikk. Pressen og den kulturelle offentligheten [Cultural Journalism. The press and the cultural public], Oslo: Scandinavian Academic Press, pp. 51-70.

JANSSEN, SUSANNE S., KUIPERS, GISELINDE and VERBOORD, MARC (2008) "Cultural Globalization and Arts Journalism: the international orientation of arts and culture coverage in Dutch, French, German, and U.S. newspapers, 1955 to 2005", American Sociological Review 73(5), pp. 719-40.

JANSSON, ANDRE' (2002) "The Mediatization of Consumption: towards an analytical framework of image culture", Journal of Consumer Culture 2(5), pp. 5-31. 
KRISTENSEN, NETE NØRGAARD (2010) "The Historical Transformation of Cultural Journalism", Northern Lights 8, pp. 69-92.

KRISTENSEN, NETE NØRGAARD and FROM, UNNI (2011) Kulturjournalistik - journalistik om kultur [Cultural Journalism - journalism on culture], Frederiksberg: Samfundslitteratur.

MCKAY, JENNY (2000) The Magazines Handbook, London: Routledge.

PATTERSON, THOMAS E. (2000) "Doing Well and Doing Good”, KSG Working Paper No. 01001, John F. Kennedy School of Government, Harvard University, Cambridge, MA.

PLASSER, FRITZ (2005) "From Hard to Soft News Standards? How political journalists in different media systems evaluate the shifting quality of news", Press/Politics 10(2), pp. 4768.

POVLSEN, KAREN K. (1995) Organisering af hverdagsliv og livsstil: Ugeblade, magasiner og fagblade [The Organization of Everyday Life and Lifestyle], Copenhagen: Medieudvalget Statsministeriet.

POVLSEN, KAREN K. (2007) “Smag, livsstil og madmagasiner [Taste, Lifestyle and food Magazines]", MediaCulture 42/43, pp. 46-53.

SCHULZ, WINFRIED (2004) "Reconstructing Mediatization as an Analytical Concept", European Journal of Communication 19(1), pp. 87-101.

SUNDVOR, EIGIL (2008) Forbrukarjournalistikk [Consumer Journalism], Kristiansand: IJforlaget.

Nete Nørgaard Kristensen (author to whom correspondence should be addressed), Department of Media, Cognition and Communication, University of Copenhagen, Njalsgade 80, 2300 Copenhagen S, Denmark. E-mail: netenk@hum.ku.dk

Unni From, Department of Information and Media Studies, Aarhus University, IT-Parken, Helsingforsgade 14, 8200 Aarhus N, Denmark. E-mail: unni@imv.au.dk 